\title{
Life Cycle Assessment Case Study: Tertiary Treatment Process Options for Wastewater Reuse
}

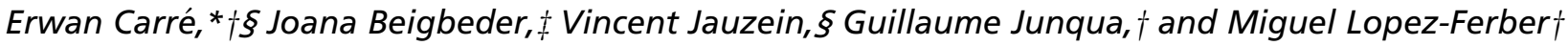 \\ †Laboratoire du Génie de l'Environnement Industriel, Ecole des Mines d'Alès, Alès Cedex, France \\ $\ddagger$ Centre des Matériaux, Ecole des Mines d'Alès, Site de Pau, Pau Cedex, France \\ ¿SAUR, Guyancourt, France
}

\begin{abstract}
Tertiary treatment process (including filtration and/or disinfection) is necessary to obtain a water quality suited for high-quality reuse from wastewater treatment. Industrial pilots representing small real-size treatment units were set up downstream of a conventional secondary treatment of a wastewater treatment plant in the South of France and their performance followed for $2 \mathrm{y}$. Life cycle assessment (LCA) methodology is used to compare the environmental impacts of different treatment processes. Five tertiary treatment trains were studied: 1) sand filtration (SF) + storage followed by ultraviolet (UV) dynamic reactor disinfection (SF-UVD), 2) sand filtration + UV batch reactor disinfection (SF-UVB), 3) ultrafiltration (UF), 4) ultrafiltration and UV batch reactor disinfection (UF-UVB), and 5) microfiltration (MF) and storage followed by dynamic UV disinfection (MF-UVD). The chosen functional unit is "To supply $1 \mathrm{~m}^{3}$ of water with a quality in compliance with the highest standard of the French reuse regulations." The combination of SF with UV disinfection or the use of UF alone was found to be equivalent in terms of environmental impact for most of the midpoint indicators chosen. Combination of UF with UV disinfection was significantly more impacting because the electricity consumption was nearly doubled. This study was conducted on an industrial pilot; it may thus be representative of industrial facilities implemented to treat higher water flows.
\end{abstract}

Keywords: Wastewater reuse Life cycle assessment (LCA) Filtration UV disinfection Multicriteria approach

\section{INTRODUCTION}

Increasing water stress is likely to occur due to population growth, industrialization, agricultural practices, and urbanization. In Southern Europe, for example, it is not infrequent to face water restrictions during summers, especially in tourist areas, to preserve the resource for potable use at the expense of recreational (green areas) or even agricultural uses. In parallel, an increase of wastewater generation is observed due to an increase in population. Thus wastewater reuse might be an appropriate response to the global water crisis (Comas Matas and Morera Carbonell 2012).

Wastewater reuse is defined by the European Commission as "the beneficial use of an appropriate quality of treated wastewater." The quality required can differ according to the intended use of reclaimed water: agriculture, urban (e.g., road cleaning), industrial, environmental (e.g., wetland preservation) or even direct use as potable water (Wintgens and Hochstrat 2006). Therefore, different tertiary treatment processes (including filtration and/or disinfection) will be necessary to meet each appropriate quality.

\footnotetext{
* Address correspondence to erwan.carre@mines-ales.fr Published 13 June 2017 on wileyonlinelibrary.com/journal/ieam.
}

Life cycle assessment (LCA), which is a normalized international methodology (ISO 2006a, 2006b), can be used as a decision support for the best treatment process option from an environmental point of view. It considers the entire life cycle, from raw materials extraction, to manufacture, distribution, use, end-of-life (treatment, recycling, disposal, etc.), and transport. Life cycle assessment is a quantitative multicriteria approach covering a large range of environmental impacts (climate change, eutrophication, resource depletion, etc.). The LCA approach is based on the definition of a functional unit (i.e., $1 \mathrm{~m}^{3}$ of treated water) to which all the impacts will be referred. The LCA starts with the compilation of a detailed inventory of all flows between the system under study (product or service) and the environment in its whole life cycle. These flows are referred to as the "functional unit." This compilation is called the "life cycle inventory" ( $\mathrm{LCl})$. The $\mathrm{LCl}$ includes the direct flows that are directly required to produce the product, but also the indirect flows, which are those required to produce the utilities like energy or the buildings. Then, the life cycle impact assessment (LCIA) methodology allows calculating the potential impacts of such a system by using a set of characterization factors that relate each flow to a set of impacts using cause-effect chains. As a result, the contribution of the system to each impact class can be estimated. Two types of analysis can be done at this level: 1) to determine what are the 
major impacts associated with a system, and 2) to determine for a given impact the relative contribution of each phase of the life cycle (extraction, production, use, dismantling, and end of life). Life cycle assessment allows comparing the environmental impacts of different options because such options will modify the inventories. Because the inventories are related to each phase of the life cycle, LCA can identify the relative contribution of each phase of life to the global environmental impact but also can analyze the effects of a substitution of one or more materials or utilities.

Life cycle assessment can be used for providing decision support when choosing between various alternatives in prospective scenarios, or to compare between various technical or organizational options providing equivalent uses. These approaches encounter a growing interest when addressing wastewater reuse (Comas Matas and Morera Carbonell 2012; Corominas et al. 2013). Amores et al. (2013) used LCA to analyze the entire urban water cycle of the city of Tarragona, Spain, including water abstraction, potable water treatment, distribution, use, wastewater collection, and treatment. Their work is placed on the perspective of increasing needs in water in the future. To satisfy those needs, various technical options were compared. They determined that in their current situation, the global warming potential (GWP) impact of the urban water cycle is distributed among water abstraction, treatment, and pumping (50\%); distribution network (35\%); and sewage network and wastewater treatment plant (WWTP) (15\%). To face water shortage, 2 scenarios were considered by the authors: wastewater reclamation and desalination. In the first scenario, no significant change on the indicators is observed, except for the reduction in freshwater abstraction. The second scenario leads to an increase of the environmental impacts of the urban water cycle. Similar results were observed by Meneses et al. (2010) when comparing different tertiary treatment processes for wastewater reclamation, traditional treatment for potable water production and desalination process. Desalination appeared as the worst option for nonpotable uses due to the high energy consumption. The addition of a tertiary treatment slightly increases the environmental impact of the WWTP, but these impacts are largely offset by the beneficial nonpotable use of reclaimed water (Pasqualino et al. 2011). Externalities (such as the energy supply mix) can have a large impact on the environmental performance of a process. Thus results of sitespecific studies are hardly generalizable. Life cycle assessment has been used as a decision-support tool to compare tertiary treatment options for wastewater reuse in a combination of pilot unit data and models to extrapolate for 20000 to 100000 person equivalents (Meneses et al. 2010; Remy et al. 2014; Baresel et al. 2015). The following treatments were studied to provide a water quality suitable for unrestricted irrigation (depending on the raw wastewater quality): chlorination plus ultraviolet (UV), media filtration plus UV, microfiltration (MF) plus UV, ultrafiltration (UF), ozonation, and ozonation plus hydrogen peroxide treatment. Scenarios including ozonation have the highest environmental impacts due to the high energy demand for ozone production and the potential ecotoxicity of byproducts (Muñoz et al. 2009; Meneses et al. 2010). High-quality effluents are produced after UF, but at the cost of high electricity and chemical demand with the associated environmental impacts (Remy et al. 2014; Baresel et al. 2015). Media filtration associated with UV disinfection seems to be a good compromise between environmental impacts and effluent quality suitable for unrestricted irrigation (Meneses et al. 2010; Pasqualino et al. 2011; Amores et al. 2013; Remy et al. 2014; Baresel et al. 2015). Preliminary coagulation with ferric chloride $\left(\mathrm{FeCl}_{3}\right)$ is often necessary to obtain the targeted effluent quality (Remy et al. 2014). Baresel et al. (2015) demonstrated that higher environmental impacts caused by higher-quality targets attainable with more advanced treatment processes become less significant when increasing plant size. Accordingly precautions must be taken, depending on whether the data come from a laboratory pilot study, a literature review, or a real case study (Lundie et al. 2004; Baresel et al. 2016).

Process data for the LCA inventory ideally should be based on trials onsite and be validated with project partners (Remy et al. 2014).

A demonstration unit was set up downstream of a municipal WWTP in southern France for $2 y$ to analyze the real function of 5 different tertiary treatment trains. The objective of the present study is to compare the environmental impacts of different options of tertiary treatment processes for water reuse in unrestricted irrigation following a conventional municipal WWTP in the South of France. The main novelty of the present work is that full-scale constructions are studied in parallel on the same site for the LCA inventory for the different options studied. The tertiary treatments were set up to provide at least $24 \mathrm{~m}^{3} / \mathrm{d}$ of treated water, that is, 100 person equivalents, assuming that 1 person consumes about $240 \mathrm{~L} / \mathrm{d}$. This size corresponds to a small village in a dispersed rural area in Mediterranean countries, where water shortage is becoming a key issue. All tertiary treatment processes are fed with water coming out from the same WWTP. After the tertiary treatments, effluent quality should comply with French regulations. We consider all effluents that comply with this standard as having equal quality. These effluents were used for irrigation in the same conditions. Accordingly, primary and secondary water treatments as well as the reuse step of irrigation are excluded from the present study because they are identical and not influenced by the technologies tested. First, the experimental platform is presented and the LCA methodology adopted is explained. Then, results of the LCA are discussed.

Such an approach allows comparing between the different technical options, and will highlight both the main potential impacts and their sources, allowing their reduction by adapting the system to each specific location. In addition, the scaling-up effects can be clearly identified. 


\section{MATERIALS AND METHODS}

\section{Experimental platform and tertiary treatment options}

An experimental platform is set up in a wastewater treatment plant in the South of France. This WWTP is based on a conventional biological process scheme and treats mainly domestic wastewaters. The pretreatment consists of grids to eliminate macro wastes and removal of grease and sands by primary clarifiers. Secondary treatment is performed by activated sludge, with advanced treatment of $N$ and $P$. Secondary effluent amounts to 0.93 million $\mathrm{m}^{3} / \mathrm{y}$ with an organic charge corresponding to 13000 person equivalents (p.e.) (considering $60 \mathrm{gBOD} 5 \cdot$ person-equivalent ${ }^{-1} \mathrm{~d}^{-1}$ ). The quality of the secondary effluent (annual mean) is characterized by low amounts of $\mathrm{N}(3-4 \mathrm{mg} / \mathrm{L}), \mathrm{P}(0.6 \mathrm{mg} / \mathrm{L})$, and suspended solids ( $<10 \mathrm{mg} / \mathrm{L}$ ). No significant seasonal change is observed.

The experimental platform aims to demonstrate different processes as tertiary treatment for reuse applications. The objective is to provide a water quality that conforms to the highest standard of the French reuse regulations (JORF 2014) (Table 1). Individual treatments (Figure 1) have been combined in 5 trains that comply with such quality standards as are studied in the current operation:

- Train 1: Sand filter (SF) and storage, then UV dynamic reactor (SF-UVD)

- Train 2: Sand filter and storage with UV static reactor (SF-UVB)

- Train 3: Ultrafiltration (UF)

- Train 4: Ultrafiltration and storage with UV static reactor (UF-UVB)

- Train 5: Microfiltration (MF) and storage, then UV dynamic reactor (MF-UVD).

Sand filtration or MF alone is not able to reach the biological quality required. And a filtration step is necessary before UV disinfection to ensure minimum contamination by suspended particles that may hinder UV light. The next paragraphs describe the different unitary processes.

The SF pilot consists of a filter body in fiberglass that contains a volume (surface: $1.05 \mathrm{~m}^{2}$ and height: $1.0 \mathrm{~m}$ ) of $1.05 \mathrm{~m}^{3}$ sand (effective size: $0.99 \mathrm{~mm}$ ). The main mechanical

Table 1. Reclaimed water quality suitable for unrestricted irrigation uses according to French regulations

\begin{tabular}{|lc|}
\hline Parameter & Threshold \\
\hline Total suspended solids $(\mathrm{mg} / \mathrm{L})$ & $<10$ \\
\hline Chemical oxygen demand $(\mathrm{mg} / \mathrm{L})$ & $<60$ \\
\hline Escherichia coli $(\mathrm{CFU} / 100 \mathrm{~mL})$ & $<250$ \\
\hline Fecal enterococci (reduction in log) & $>4$ \\
\hline F-RNA coliphages (reduction in log) & $>4$ \\
\hline Sulfite-reducing bacteria (reduction in log) & $>4$ \\
\hline
\end{tabular}

$\mathrm{CFU}=$ colony forming units; $\mathrm{F}-\mathrm{RNA}=\mathrm{RNA}$ bacteriophages. elements are a centrifuge pump for raw water feeding, a centrifuge pump for washing, and an air blower also for washing. An air compressor allows operation of pneumatic valves. A peristaltic pump allows $\mathrm{FeCl}_{3}$ injection as a coagulant. The production flow is fixed at $10 \mathrm{~m}^{3} / \mathrm{h}$. The washing cycle is set every $24 \mathrm{~h}$ or when there is a differential pressure between entry and output higher than 0.3 bars. It consists of sand decompression with air, backwashing, and forward flushing.

The MF pilot consists of 1 module containing a nylon membrane of porosity ranging from 0.2 to $25 \mu \mathrm{m}$ (depending on the filtration cake formation). The main mechanical elements are a centrifuge pump for raw water feeding and a centrifuge pump for washing. An air compressor allows operation of pneumatic valves and air injection for washing. The production flow is fixed at $1.8 \mathrm{~m}^{3} / \mathrm{h}$. There is 1 washing cycle per hour, which consists of air injection, backwashing, and forward flushing.

The UF pilot consists of 2 modules (diameter of $20 \mathrm{~cm}$ and height of $2 \mathrm{~m}$ ), which contain hollow fibers, accounting for a total surface of $40 \mathrm{~m}^{2}$ per module. Each fiber has a porosity of $0.025 \mu \mathrm{m}$. The main mechanical elements are a centrifuge pump for raw water feeding and a centrifuge pump for washing. Two air compressors allow operation of pneumatic valves and air injection for washing. Four peristaltic pumps allow $\mathrm{FeCl}_{3}$ injection as a coagulant and other chemicals (acid, soda, and bleach) for membrane washing. The production flow is fixed at $3 \mathrm{~m}^{3} / \mathrm{h}$. There are several types of washing cycles: simple hydraulic washing (W1) every $20 \mathrm{~min}$ of production, complete hydraulic washing (W2, every two W1), and chemical washing (W3, every ten W2).

Two different units of UV-based sterilization were tested, named "UV Batch" (UVB) and "UV Dynamic" (UVD). They were designed and built by Bio UV (Lunel, France) to ensure the required microbiological quality level in standard operation. They were experimentally tested during the 2-y operation. The UVB consists of a high density polyethylene (HDPE) storage tank of $6 \mathrm{~m}^{3}$ (Figure 1). Inside the tank, a stainless steel structure of the height of the tank holds 2 lowpressure c-type Ultra Violet (UVc) lamps in the top and 2 lamps in the bottom, for a total electric power of $348 \mathrm{~W}$. A motor allows the rotation of the structure, aiming to treat the entire volume. The system runs for $10 \mathrm{~min}$ every $30 \mathrm{~min}$ and is stopped during filling and emptying of the tank. The water to be treated stays in the tank for at least $6 \mathrm{~h}$.

The UVD consists of the same storage tank, followed by a UV dynamic reactor outside the tank, which is a stainless steel cylinder containing 3 low-pressure UVc lamps, for a total electric power of $900 \mathrm{~W}$. The maximum water flow admissible in the system is $10 \mathrm{~m}^{3} / \mathrm{h}$. The lamps run only during demand for irrigation. Both disinfection systems include the same model of centrifuge pump for water distribution.

Life cycle assessment

Goal and scope. International standards ISO 14040 and ISO 14044 (International Organization for Standardization [ISO] 


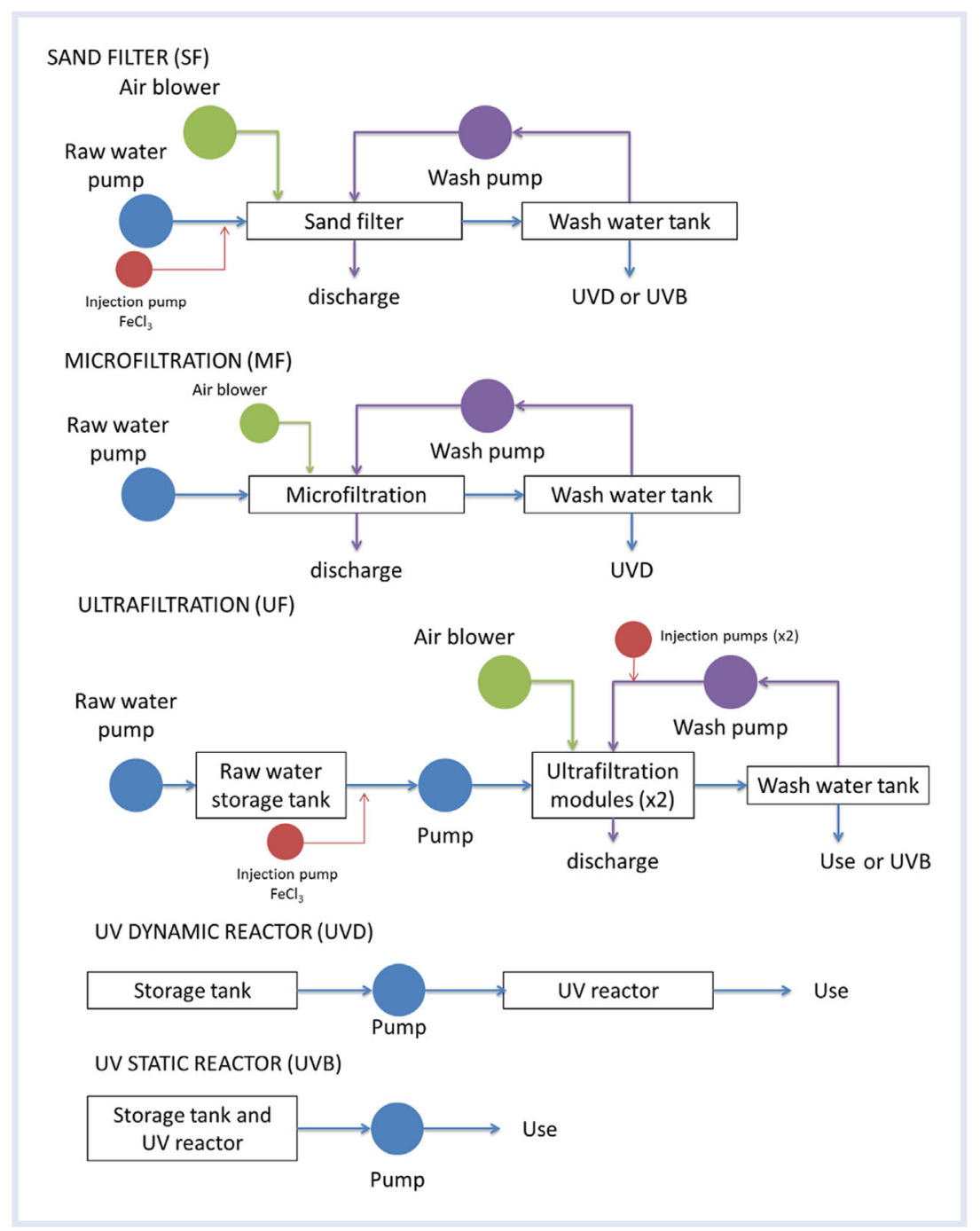

Figure 1. Individual components that are assembled to constitute the 5 treatment trains.

2006a, 2006b) have been followed in order to perform the LCA.

The goal of the present study is to compare these different tertiary treatment options of water reuse. The functional unit chosen refers to $1 \mathrm{~m}^{3}$ of water supplied with a quality in compliance with the highest standard of the French reuse regulations. Accordingly, all waters that comply with this standard are considered to be of equivalent quality. The differences in the capacity and lifespan of each pilot have been taken into account to define the reference flows related to the functional unit.

The definition of the boundaries of the system consists of determining what processes are integrated or excluded from the analysis, and until which level of details. In the present study, LCA focuses on the inputs and the outputs of the tertiary treatment processes and considers neither the primary or secondary treatment of the wastewater plant nor the different technologies of irrigation. For each option, the system is decomposed into the following steps: pilots manufacturing, transport, utilization, and end of life (Figure 2). Transport of the pilot units to the experimental site, and

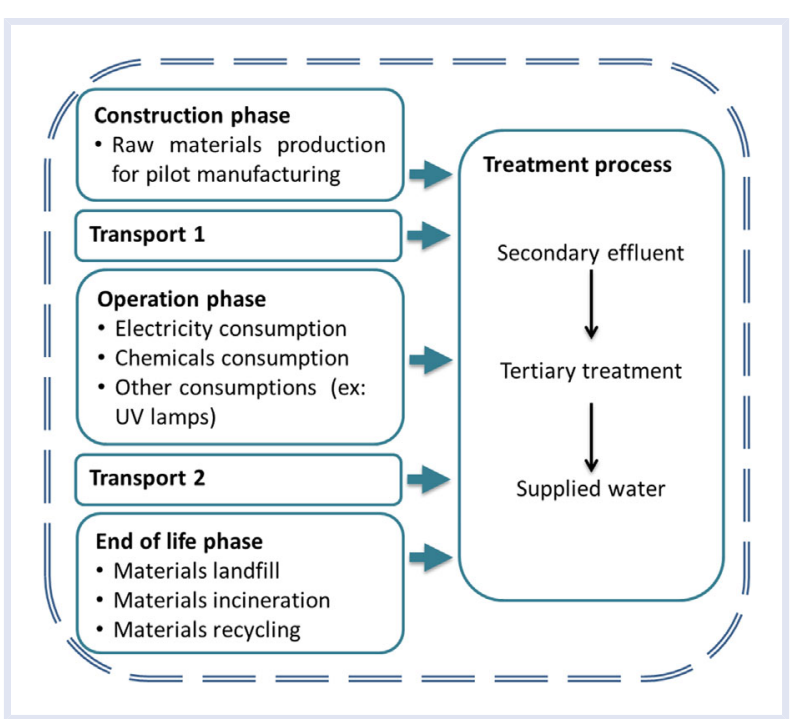

Figure 2. Boundaries of the systems studied for life cycle inventory. 
transport when dismantling, are considered within the boundaries. However, during the modeling, the impacts due to the transportation, the energy mix, and the materials composing the storage tanks have been considered individually because they can vary according to the local conditions.

Inventory. Inventory has mainly used processes from Ecoinvent v2.2 database (Frischknecht et al. 2005). The PE International database, included in Gabi software v5, has been used for processes unavailable on Ecoinvent (PE International 2013).

The construction phase of the pilots is assimilated to materials production. The raw materials forming and assembling steps are considered negligible. The nature of the different components of the pilots and their weight are supplied by the manufacturers. When a material is not present in the databases, a material with approaching chemical structure or with a similar use is selected (for details, see Supplemental Data, Annex 1). Weights of the materials used for the construction step are presented in Supplemental Data (Annex 3).

Inventory data for the operation phase take into account the consumptions in electricity, chemicals (including transport), and other consumables. Life cycle inventory references for the operation phase are presented in Supplemental Data (Annex 2). Weights of the materials used for the operation phase are also presented in Supplemental Data (Annex 4).

Concerning the pilots' end of life, a transport step is considered between the utilization site and pilot dismantling facility: A distance of $100 \mathrm{~km}$ was arbitrarily chosen as the worst hypothesis. Previous studies (ADEME 1997) indicated that the average distance for waste transport in metropolitan
France is around $43 \mathrm{~km}$. The real distances from the pilot plant to waste treatment sites is between 12 and $109 \mathrm{~km}$, depending on the hazard level of the waste. The end-of-life treatment of all metal materials is modeled using the Ecoinvent process representing the construction building steel dismantling. In France, a small proportion of plastic waste is recycled ( $<20 \%)$; the rest is distributed between incineration and landfill (Defranceschi and Poisson 2015). In our case study, because the plastic used did not represent a consequent fraction of the total waste, recycling was not considered. Half of plastic waste is supposed to be incinerated, and the other half is supposed to be landfilled (The French Environment and Energy Management Agency Estimation ADEME 2014). These steps are modeled through Ecoinvent processes. Avoided impacts are associated with the production of recycled materials and with power recovery by incineration of plastics.

Impact assessment. Models for impact evaluation of each option are built with the Thinkstep software Gabi v5. Previous studies related to water reuse alternatives allow the definition of a set of midpoint indicators linked to terrestrial acidification (AP), global warming (GWP), terrestrial eutrophication $(E P)$, photochemical oxidation (PhO), metal depletion (MD), ozone depletion (OD), fossil resources depletion (FD), effect on living organisms (ecotoxicity [ETP] and human toxicity [HTP], marine and freshwater eutrophication [MEP and FEP], $A P)$, ionizing radiation (IR), and the primary energy consumption (PEC, also called "cumulative energy demand") (Meneses et al. 2010; Pasqualino et al. 2011; Amores et al. 2013; Remy et al. 2014; Baresel et al. 2015). These authors used the CML method developed by the Centrum voor

Table 2. Environmental profile of the supply of $1 \mathrm{~m}^{3}$ of water with a quality in compliance with the highest standard of the French reuse regulations for the 5 tertiary treatment chain options studied ${ }^{a}$

\begin{tabular}{|c|c|c|c|c|c|}
\hline Impact category & SF-UVD & SF-UVB & UF & UF-UVB & MF-UVD \\
\hline HTP (kg 1,4-DB) & 4.5E-02 & 4.4E-02 & 4.6E-02 & 7.6E-02 & $6.8 \mathrm{E}-02$ \\
\hline IR (kg U235 eq.) & 4.4E-01 & 5.3E-01 & 4.3E-01 & 7.8E-01 & 4.9E-01 \\
\hline $\mathrm{PhO}$ (kg NMVOC) & 5.4E-04 & $5.5 \mathrm{E}-04$ & 6.7E-04 & 1.0E-03 & $1.2 \mathrm{E}-03$ \\
\hline GWP $(\mathrm{kg} \mathrm{CO} 2)$ & 2.2E-01 & 2.3E-01 & $2.5 \mathrm{E}-01$ & 4.1E-01 & 4.2E-01 \\
\hline ETP (kg 1,4-DB eq.) & 4.7E-03 & 4.8E-03 & 4.2E-03 & 7.9E-03 & 7.5E-03 \\
\hline MEP (kg N eq.) & 8.0E-04 & 8.1E-04 & 4.1E-03 & $4.2 \mathrm{E}-03$ & $5.4 \mathrm{E}-03$ \\
\hline FEP (kg P eq.) & 8.5E-05 & $9.5 \mathrm{E}-05$ & $2.5 \mathrm{E}-04$ & 3.0E-04 & $3.2 \mathrm{E}-04$ \\
\hline $\mathrm{AP}(\mathrm{kg} \mathrm{SO})$ & 9.8E-04 & $9.5 \mathrm{E}-04$ & 1.3E-03 & 2.0E-03 & 2.1E-03 \\
\hline FD (kg oil eq.) & 7.1E-02 & 7.3E-02 & 5.1E-02 & $1.1 \mathrm{E}-01$ & 1.1E-01 \\
\hline MD (kg Fe eq.) & 5.9E-02 & 3.9E-02 & $5.2 \mathrm{E}-02$ & 8.1E-02 & 1.1E-01 \\
\hline PEC (MJ) & $1.5 \mathrm{E}+01$ & $1.7 \mathrm{E}+01$ & $1.4 \mathrm{E}+01$ & $2.5 E+01$ & $1.8 \mathrm{E}+01$ \\
\hline
\end{tabular}

$A P=$ terrestrial acidification; $E T P=$ ecotoxicity (measured as 1,4-Dichlorobenzene, 1,4-DB equivalents); FD = fossil resources depletion; FEP = freshwater eutrophication; GWP = global warming potential; HTP=human toxicity; IR=ionizing radiation; $M D=$ metal depletion; MEP= marine eutrophication; MF$\mathrm{UVD}=$ microfiltration-UV disinfection; $\mathrm{NMVOC}=; \mathrm{PEC}=$ primary energy consumption; PhO= photochemical oxidation (measured as kg of Non-Methane Volatile Organic Compounds, NMVOC); SF-UVB = sand filtration + UV batch reactor disinfection; SF-UVD = sand filtration + storage followed by ultraviolet dynamic reactor disinfection; UF = ultrafiltration; UF-UVB = ultrafiltration and UV batch reactor disinfection.

aDetailed information on each indicator is given in Supplemental Data, Annex 5. 
Milieukunde der Universität Leiden except for Remy et al. (2014), who have used the ReCiPe LCIA method, which combines evaluation at midpoint and endpoint levels (Goedkoop et al. 2013). In addition to being more recent, the $\mathrm{ReCiPe}$ method is more suitable for the European zone. Remy et al. (2014) do not use indicators related to MEP, OD, $\mathrm{PhO}$ considered as not important or negligible; and freshwater use, considering that the quantitative part of this last indicator is the same for all scenarios and that the qualitative part already included in the other indicators, could lead to double counting.

In the present study, we have selected HTP, IR, PhO, GWP, ETP, MEP, FEP, AP, FD, MD, and PEC as most appropriate indicators based on these previous studies. Metal depletion was selected because components of certain tertiary treatment processes use scarce resources. The use of photochemical oxidation process and plastic materials required selecting $\mathrm{PhO}$. Lastly, we have selected IR due to the French electricity mix, including a large part of nuclear electricity. A freshwater use-related indicator was not selected because we were in the same circumstances as Remy et al. (2014). The impacts were assessed for the European zone with the ReCiPe method and Gabi v5. Reference units are presented in Supplemental Data (Annex 5).

\section{RESULTS AND DISCUSSION}

\section{Normalization and global comparison}

The detailed environmental profile of the 5 trains is presented in Table 2. The results for the SF-UVD train are comparable to those obtained by Meneses et al. (2010) for a slightly different treatment train with additional coagulationfloculation and chlorination steps, and considering another energy mix (Spain instead of France, in our case). In the same way, the results obtained for the UF-UVB train can be compared to the work of Baresel et al. (2015), even if the treatment chain includes another configuration for UV disinfection and an additional chlorination. Energy consumption in the use phase appears to be a key differentiating factor between treatments. Because the environmental impacts of energy are variable between countries in relation to their electricity mix, this point should be taken into account when choosing the treatment for a given location. It also conditions the main indicators chosen as representative for the environmental impact. For instance, Spain's electricity mix presents higher environmental impacts than does France's for the main studied impacts, except for the IR potential.

To obtain a global comparison in a first approach, indicator results are normalized to the total environmental impacts per person in Europe (ReCiPe data, reference year: 2000) (Goedkoop et al. 2013). This normalization gives information on the relative contribution of each option studied to each category of environmental impact, allowing comparison between trains (Figure 3). The GWP is involved in impacts on both human health and ecosystems. The most impacting options regarding all the midpoint indicators chosen are UF-UVB and MF-UVD. Impacts of SF-UVD, SF-UVB, and UF are comparable, except for

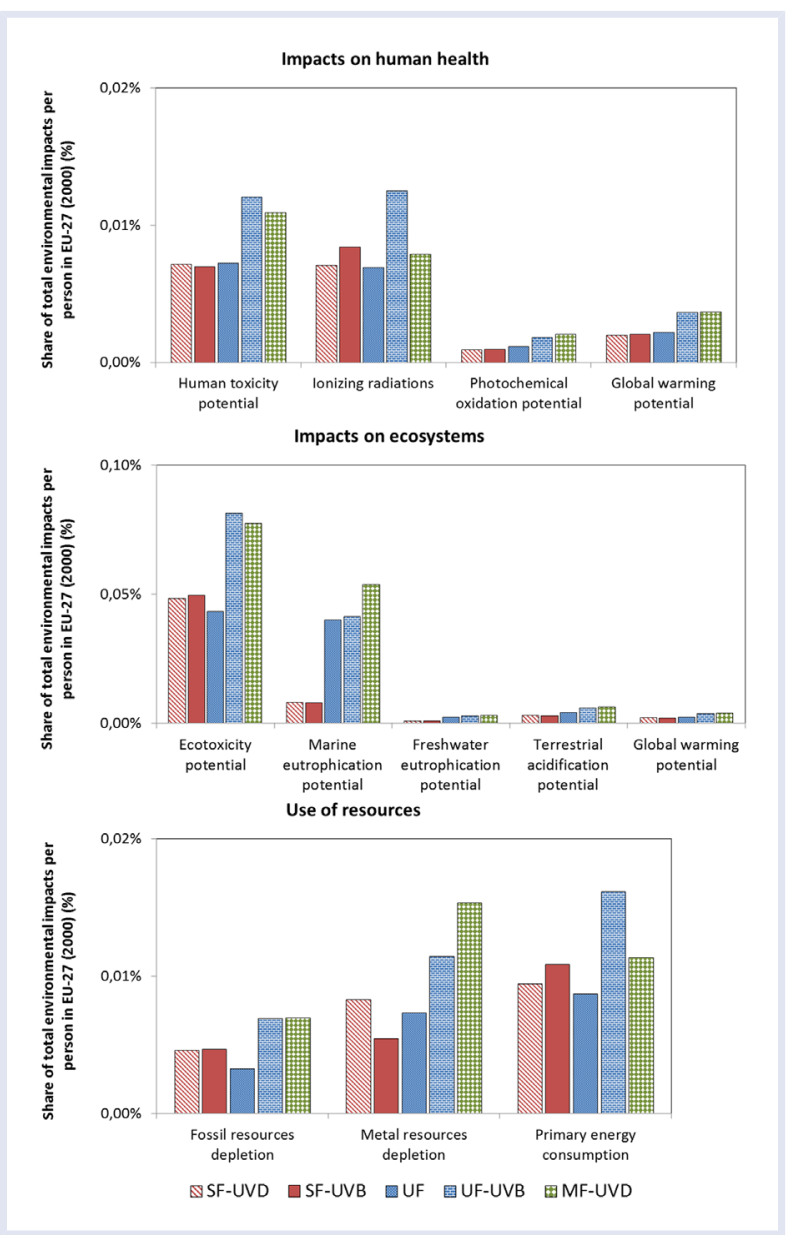

Figure 3. Relative share of each treatment train to the endpoint protection areas. The aggregated impacts have been normalized per person in EU27 using ReCiPe (reference year 2000). MF-UVD = microfiltration-UV disinfection; SF-UVB = sand filtration + UV batch reactor disinfection; SF-UVD = sand filtration + storage followed by ultraviolet dynamic reactor disinfection; UF=ultrafiltration; UF-UVB $=$ ultrafiltration and UV batch reactor disinfection.

the marine eutrophication indicator, where the UF option is more impacting. This can be explained by the concentration of $\mathrm{N}$ in the membrane during the filtration, which increases the potential eutrophication impact of wash water. The $\mathrm{N}$ comes from the secondary-treated wastewater. It is not retained by the other filtration processes studied. Hence, the impact of the $\mathrm{N}$ content of the supplied water was not considered because it was under the permissible limits for the intended uses.

Except for the MF-UVD option, the differences observed are mainly explained by electricity consumption: around 1 kWh per cubic meter supplied for the SF-UVD, SF-UVB, and UF options, and around $2 \mathrm{kWh}$ per cubic meter supplied for the UF-UVD option.

Remy et al. (2014) also concluded that environmental impact of SF-UV disinfection and ultrafiltration are similar, even if the study was focused on the removal of phosphorus. Baresel et al. (2015) found that the environmental impacts of UF-UV are higher than SF-UV, which is also in accordance in our results. The only divergence is on the GWP indicator, which is significantly higher for SF than for UF in their studies. These authors justified that result by incomplete nitrification 
during the secondary treatment, leading to higher emissions of nitrous oxide $\left(\mathrm{N}_{2} \mathrm{O}\right)$, a high-GWP gas. In our case, complete nitrification occurs in the aeration tank during the secondary treatment (data not shown). That is why no significant change is observed in total $\mathrm{N}$ concentration before and after the SF.

\section{Detailed environmental profile}

For a thorough understanding of the differences between the 5 trains, decomposition into the life phases previously defined was carried out for SF-UVD and UF (Figure 2). For the MF-UVD option in our conditions, transport impacts are not negligible because the MF pilot was manufactured in Korea and transported by plane. This causes the emission of organic halogen compounds, $\mathrm{NOx}$, and $\mathrm{CO}_{2}$ responsible for photochemical oxidant formation and climate change. Fuel consumption during transport is also responsible for fossil resource consumption. A transport by boat from Korea would reduce the impact of the transport step. However, the use phase (energy consumption) is still the most impacting step of the process. The MF-alone profile is quite similar to that of UF, but it does not reach the quality level required. Accordingly, it needs always to be complemented by UV. Such train implies increased electric energy consumption (Figure 3).

Decomposition results were comparable for the SF-UVD and SF-UVB options (Figure 4 shows the results for SF-UVD). For most impacts considered, the operation phase is the most impacting step, with electricity generation being the main contributor. The transport step has a minor impact on the set of indicators. The construction phase of the pilots is the major contributor to ecotoxicology, fossil resources depletion, and metal depletion. Concerning terrestrial ecotoxicity, it is mainly the production of stainless steel that composes the UVD and the UF reactors, especially present in the UV disinfection reactor, which is a source of heavy metal emission in the air (Ag). The manufacturing process of the polytetrafluoroethylene (PTFE), used to model the polyvinylidene fluoride (PVDF), has a significant photochemical oxidation potential and may lead to terrestrial acidification. The end-of-life phase of the UV reactor causes a significant proportion of marine and freshwater ecotoxicity; this is explained by the significant presence of polyethylene (storage tank), containing $\mathrm{V}$ (catalyst) that is released during end-of-life treatments (landfill and incineration). Recycling of metals allows avoiding depletion of metal resources, representing $27 \%$ of the total impact of the SF-UVD option for this indicator. For other studied environmental impacts, those avoided in later life are less noticeable.

The same trend as in previous options is observed with UF (Figure 4). Indeed, the operation phase is the main contributor, mainly due to electricity consumption. The use of stainless steel for the construction phase has a significant impact on ecotoxicity. The manufacturing of membrane materials (mainly polyethersulfone) has a significant impact on photochemical oxidation and global warming. During the operation phase, a small part of $\mathrm{N}$ and $\mathrm{P}$ is retained in the membrane, increasing the eutrophication potential of the washing effluent. Transport and end-of-life steps are low contributors to environmental impacts. Avoided impacts are

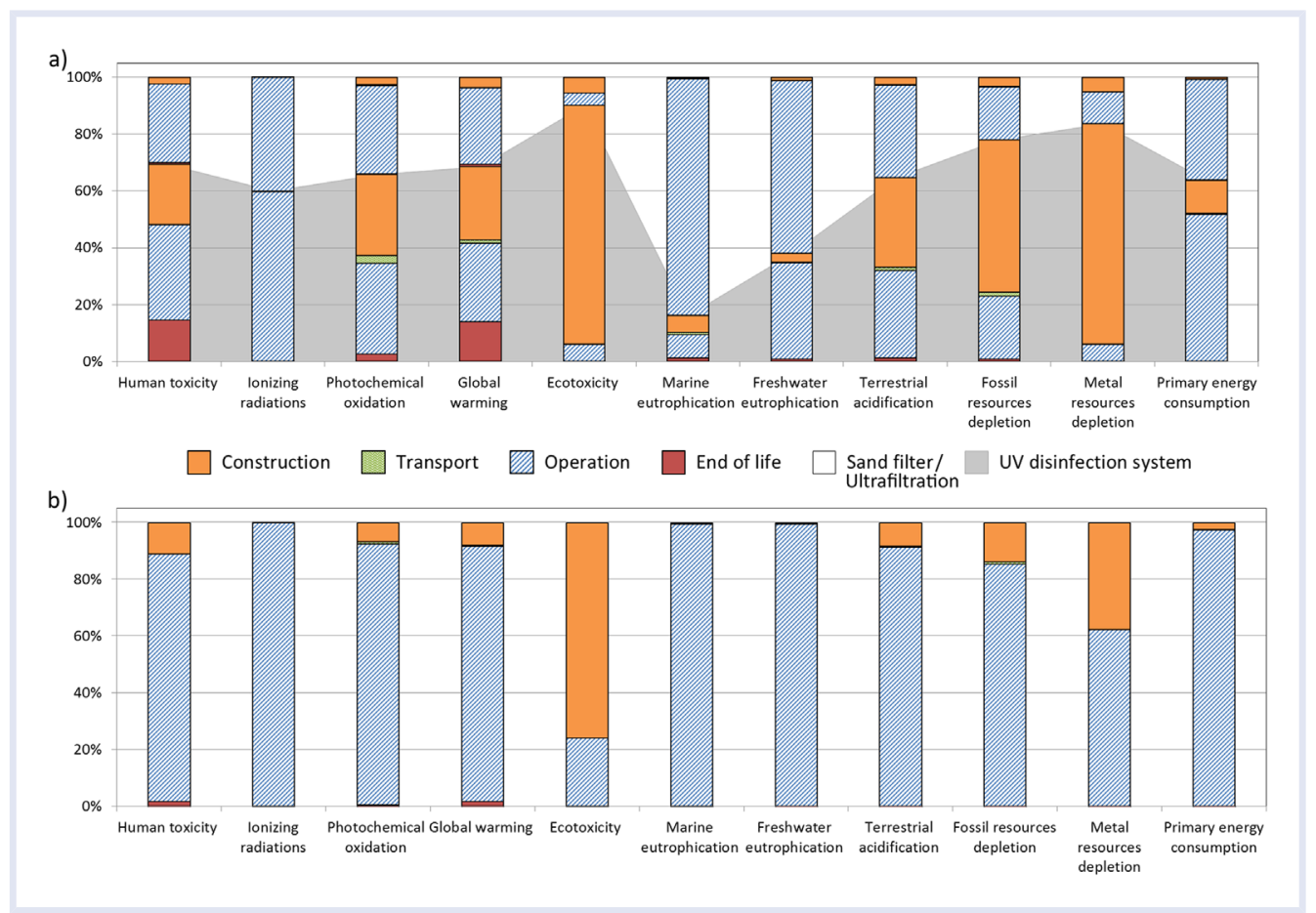

Figure 4. Detailed environmental profile of the SF-UVD (a) and UF alone (b). The relative contributions of the SF (white background) and UV (grey background) to the total environmental load are separated in panel a. SF-UVD = sand filtration + storage followed by ultraviolet dynamic reactor disinfection; UF = ultrafiltration. 
mainly constituted by preservation of metal resources ( $15 \%$ of the total impact of the UF option for this indicator).

\section{CONCLUSION}

Life cycle assessment was used as a tool to compare 5 trains of tertiary treatment processes for high-quality wastewater reuse operating in the South of France. For most of the studied criteria, the use phase is globally the most impacting, although for some criteria, such as metal resources exhaustion, the construction phase of the pilots is the major contributor, depending on the nature of the materials used.

The use of robust technology such as SF followed by UVB (SF-UVD and SF-UVB) has an environmental impact equivalent to UF alone for most of the midpoint indicators chosen. Ultrafiltration is usually complemented with a sterilization module, to prevent pollution in case of fiber break. If this option is considered, the environmental load is clearly favorable to SF-UVB to produce water for unrestricted irrigation according to the French requirements. Concerning the MF pilot, its transport from Korea increases the impact of the MF-UVD option for most of the indicators. The quality of the output water does not allow a standalone operation, without a UV treatment downstream, making such assembly more impacting than SF-UVB.

Because the use phase is the major contributor, changes in the construction phase will result in a limited improvement. For example, comparing the impacts of changing HDPE tanks to concrete tanks reveals that the fossil depletion indicator is reduced in the latter by 7\%; all other indicators are almost equivalent. Reported to the whole life cycle, no significant modification is observed. The use of PTFE or PVDF is difficult to avoid because these materials are necessary to protect mechanical pieces (e.g., pumps) in contact with corrosive chemicals.

The environmental impact of the process is only one of the criteria that would be taken into account when choosing a given technology in a given location. Both construction and operation costs often constitute the major criteria. Such costs have been estimated in a recent paper for Spanish conditions (Iglesias et al. 2010). These authors obtain approximately similar costs of operation for filtration + disinfection and deep filtration $\left(0.04 € / \mathrm{m}^{3}-0.07 € / \mathrm{m}^{3}\right)$, and slightly higher investment for $\mathrm{SB}+\mathrm{UV}$ than UF alone $\left(9-22 € / \mathrm{m}^{3}\right.$ produced per day compared to $5-11 € / \mathrm{m}^{3}$ produced per day). A third criterion is the technicity requirement. Ultrafiltration systems require far more technicity for both operation and maintenance than does SF+UV. For small units located in dispersed habitats, the availability of highly skilled technicians might constitute a limiting factor to run and survey UF systems. In the event of a membrane break, absence of detection would compromise the final quality of the water, whereas SF+UV is largely more tolerant.

The present study was conducted on industrial pilot scale; thus it may be representative of industrial facilities implemented to treat higher water flows. For instance, the number of treatment trains working in parallel may be increased to increase the treatment capacity.
Acknowledgment-This study was conducted with financial support of the French Ministry of Industry. The authors would also like to thank the Association Nationale de la Recherche et de la Technologie (ANRT) for their funding of Erwan Carré's PhD fellowship.

Data Accessibility—Data are available from Erwan Carré (erwan.carre@mines-ales.fr). Models for impact evaluation were built by using Gabi software version 5 (http://www.gabisoftware.com) and 2 databases: PE International database included in Gabi software, and Ecoinvent version 2.2 (http://www.ecoinvent.org/).

\section{SUPPLEMENTAL DATA}

Annex 1. Life cycle inventory references for the materials used for the construction phase of the pilots.

Annex 2. Life cycle inventory references for the operation phase.

Annex 3. For each process studied, weight (in kilograms) of materials used for the construction phase reduced to the functional unit.

Annex 4. For each option studied, inventory data for the operation phase reduced to the functional unit.

Annex 5. Reference units of the environmental impacts chosen.

\section{REFERENCES}

[ADEME] Agence de l'environnement et de la matrise de l'énergie. 1997. La logistique et le transport des déchets ménagers, agricoles et industriels (Logistics and transport of municipal, agricultural and industrial waste) [French]. Paris (FR): The French Environment and Energy Management Agency.

[ADEME] Agence de l'environnement et de la matrise de l'énergie. 2014. Analyse de la chaîne de valeur du recyclage des plastiques en France -synthèse. (Chain value analysis of plastic recycling in France. Synthesis). Paris (FR): The French Environment and Energy Management Agency.

Amores MJ, Meneses M, Pasqualino J, Antón A, Castells F. 2013. Environmental assessment of urban water cycle on Mediterranean conditions by LCA approach. J Clean Prod 43:84-92. DOI:10.1016/j. jclepro.2012.12.033

Baresel C, Dahlgren L, Almemark M, Lazic A. 2015. Municipal wastewater reclamation for non-potable reuse environmental assessments based on pilot-plant studies and system modelling. Water Sci Technol 72(9):1635-1643. DOI:10.2166/wst.2015.373

Baresel C, Dahlgren L, Almemark M, Lazic A. 2016. Environmental performance of wastewater reuse systems: Impact of system boundaries and external conditions. Water Sci Technol 73(6):1387-1394. DOI:10.2166/ wst.2015.624

Comas Matas J, Morera Carbonell S. 2012. Life cycle assessment and water management-related issues. Girona (ES): Documenta Universitaria. $229 \mathrm{p}$.

Corominas L, Foley J, Guest JS, Hospido A, Larsen HF, Morera Carbonell S, Shaw A. 2013. Life cycle assessment applied to wastewater treatment: State of the art. Water Res 47(15):5480-5492. DOI:10.1016/j. watres.2013.06.049

Defranceschi M, Poisson R. 2015. Les catalyseurs à base métallique et les retardateurs de flamme bromés dans les plastiques: leur devenir dans les filières de gestion des déchets (Metal catalysts and brominated flame retardants in plastics: their behavior in waste management plants) [French]. RECORD. 13-0150/1A. https://www.record-net.org/storage/etudes/130150-1A/synthese/Synth_record13-0150_1A.pdf

Frischknecht R, Jungbluth N, Althaus HJ, Doka G, Dones R, Hellweg S, Hischier R, Nemecek T, Rebitzer G, Spielmann M et al. 2005. The ecoinvent 
database: Overview and methodological framework. Int J LCA 10(1): 112-122. DOI:10.1065/lca2004.10.181.1

Goedkoop M, Heijungs R, De Schryver A, Struijs J, Van Zelm R. 2013. ReCiPe 2008: A LCIA method which comprises harmonised category indicators at the midpoint and the endpoint level. The Hague (NL): Ministry of Environment. $126 \mathrm{p}$.

Iglesias R, Ortega E, Batanero G, Quintas L. 2010. Water reuse in Spain: Data overview and cost estimation of suitable treatment trains. Desalination 263:1-10.

[ISO] International Organization for Standardization. 2006a. Environmenta management - Life cycle assessment - Principles and framework. Geneva (CH). ISO 14040.

[ISO] International Organization for Standardization. 2006b. Environmenta management - Life cycle assessment - Requirements and guidelines. Geneva (CH). ISO 14044.

JORF. 2014. Arrêté du 25 juin 2014 modifiant l'arrêté du 2 août 2010 relatif à l'utilisation d'eaux issues du traitement d'épuration des eaux résiduaires urbaines pour l'irrigation de cultures ou d'espaces verts (French order of 2014, related to the use of water from treated urban wastewater for irrigation of crops and green areas) [French]. J Off la République Française 153(4 juillet 2014):11059-11069.
Lundie S, Peters GM, Beavis PC. 2004. Life cycle assessment for sustainable metropolitan water systems planning. Environ Sci Technol 38(13):3465-73. DOI:10.1021/es034206m

Meneses M, Pasqualino JC, Castells F. 2010. Environmental assessment of urban wastewater reuse: Treatment alternatives and applications. Chemosphere 81(2):266-272. DOI:10.1016/j.chemosphere.2010.05.053

Muñoz I, Rodŕguez A, Rosal R, Fernández-Alba AR. 2009. Life cycle assessment of urban wastewater reuse with ozonation as tertiary treatment: A focus on toxicity-related impacts. Sci Total Environ 407(4):1245-1256. DOI:10.1016/j scitotenv.2008.09.029

Pasqualino JC, Meneses M, Castells F. 2011. Life cycle assessment of urban wastewater reclamation and reuse alternatives. J Ind Ecol 15(1):49-63. DOI:10.1111/j.1530-9290.2010.00293.x

PE International. 2013. Gabi software with built-in database v5. Leinfelden (DE): Thinkstep.

Remy C, Miehe U, Lesjean B, Bartholomäus C. 2014. Comparing environmental impacts of tertiary wastewater treatment technologies for advanced phosphorus removal and disinfection with life cycle assessment. Water Sci Technol 69(8):1742-50. DOI:10.2166/wst.2014.087

Wintgens T, Hochstrat R. 2006. Report on integrated water reuse concepts. In: Integrated concepts for reuse of upgraded wastewater. Aachen (DE): AQUAREC European project. 184 p. 